\title{
O JORNAL DAS BAND DA DEUTSCHE HILFSVEREINSSCHULE E AS ESCRITAS ESCOLARES SOBRE IMIGRAÇÃO ALEMÃ (COLÉGIO FARROUPILHA/RS, 1929-1938)
}

\author{
Alice Rigoni Jacques \\ Colégio Farroupilha, Brasil. \\ Lucas Costa Grimaldi \\ Pontifícia Universidade Católica do Rio Grande do Sul, Brasil.
}

\begin{abstract}
Resumo
O presente estudo analisa o jornal Das Band, editado pelos estudantes e professores da Deutsche Hilfsvereinsschule, Colégio Farroupilha/RS, no período de 1929-1938. A pesquisa contextualiza a história da escola, a produção e circulação do jornal e, especialmente, as escritas produzidas pelos estudantes do curso primário e do curso ginasial sobre o tema imigração alemã, que constroem uma discursividade de enaltecimento da participação alemã no povoamento do Rio Grande do Sul.

Palavras-chave: jornal escolar, cultura escolar, imigração alemã.
\end{abstract}

\section{THE DAS BAND NEWSPAPER AT DEUTSCHE HILFSVEREINSSCHULE AND SCHOOLS WRITTENS ABOUT GERMAIN IMIGRATION (COLÉGIO FARROUPILHA/RS, 1929-1938)}

\begin{abstract}
This study analyzes the newspaper Das Band, edited by students and teachers of Deutsche Hilfsvereinsschule, Colégio Farroupilha/RS, in the period 1929-1938. The research describes the history of the school, the production and circulation of the newspaper and especially the writings produced by students of primary and middle school on german immigration, which build a discourse of glorification of German participation in the settlement Rio Grande do Sul. Key-words: school newspaper, school culture, german immigration.
\end{abstract}




\section{EL PERIÓDICO DAS BAND DE DEUTSCHE HILFSVEREINSSCHULE Y LAS ESCRITAS DE LA ESCUELA SOBRE LA INMIGRACIÓN ALEMANA (COLÉGIO FARROUPILHA/RS, 1929-1938)}

Resumen

Este estudio analiza el periódico Das Band, editado por los estudiantes y profesores de Deutsche Hilfsvereinsschule, Coléegio Farroupilha/RS, en el período 1929-1938. La investigación describe la historia de la escuela, la producción y la circulación del periódico y en especial los escritos producidos por los alumnos de la escuela primaria y secundaria sobre la inmigración alemana, que construyen un discurso de exaltación de la participación alemana en el asentamiento Rio Grande do Sul.

Palabras-clave: periódico escolar, la cultura escolar, la inmigración alemana.

\section{LE JOURNAL DAS BAND DU DEUTSCHE HILFSVEREINSSCHULE ET ESSAIS SCOLAIRES SUR L'IMMIGRATION ALLEMANDE (COLÉGIO FARROUPILHA/RS, 1929-1938)}

Résume

Cette étude analyse le journal Das Band édité par les étudiants et les périodique enseignants de la Deutsche Hilfsvereinsschule, Colégio Farroupilha/RS, pour la période 1929-1938. La recherche décrit l'histoire de l'école, la production et la diffusion du journal et, en particulier, les écrits produits par les élèves de l'école primaire et au collège sur l'immigration allemande, qui construisent un discours de glorification de la participation allemande dans le règlement Rio Grande do Sul. Mots-clé: presse scolaire, écrites scolaire, l'immigration allemande. 


\section{Introdução}

imprensa escolar corresponde a um campo de investigação da História da
Educação que procura analisar a produção dos estudantes e a difusão dos
conhecimentos por meio de jornais ou revistas.

Com a abertura do país à imigração, logo se pôde sentir a presença do imigrante na imprensa. Nas primeiras levas de imigrantes, que chegam a São Leopoldo/RS em 1824, encontra-se a profissão de impressor e fabricante de papel. Desde 1836 foram publicados jornais em língua alemã no Rio Grande do Sul.

O primeiro deles se chamou O Colono Alemão e foi editado por Hermann Von Salisch, adversário do diretor da Colônia Alemã de São Leopoldo, dr. João Daniel Hillebrand. Seu primeiro número foi lançado em 3 de fevereiro de 1836. Teve vida breve. Após a Revolução Farroupilha, novo jornal seria lançado em 10 de agosto de 1852, em Porto Alegre, por José Cândido Gomes. Trata-se do Der Colonist. Wochenblatt fuer Handel, Gewerb und Landbau (O Colono. Semanário para Comércio, Indústria e Agricultura), que existiu até 1853, ano em que foi substituído pelo Der Deutsche Einwanderer (O Imigrante Alemão), jornal originalmente editado no Rio de Janeiro com o apoio do governo imperial e transferido para Porto Alegre em 1854.

No entanto, talvez o mais importante jornal em língua alemã, editado em Porto Alegre, foi o Deutsche Zeitung (Jornal Alemão) (1861-1917), administrado por comerciantes porto-alegrenses: Lothar de la Rue, Frederico Hänsel, Julius Wollmann, Richard Huch, Jakob Rech, Emil Wiedemann e Wilhelm ter Brüggen ${ }^{1}$. Teve como redator Carlos Von Koseritz, ${ }^{2}$ que Ihe deu notável desenvolvimento. Koseritz fundaria, em 1881, seu próprio jornal, Koseritz' Deutsche Zeitung (Jornal Alemão de Koseritz), por ele dirigido até 1890 (Dreher, 2004).

Com o incremento da imigração surgiram outros jornais, nos quais se refletiram as mais diversas correntes ideológicas, filosóficas, políticas e religiosas. A eles se agregaram almanaques, revistas, livros, jornais escolares e todo um conjunto que espera pela recolha para que se reconstrua a história da imprensa alemã no Rio Grande do Sul (Dreher, 2004).

O presente estudo ${ }^{3}$ analisa o jornal Das Band, editado pelos estudantes e professores da Deutscher Hilfsvereinsschule (Colégio Farroupilha/RS), no período de 1929-1938. Os exemplares fazem parte do acervo da escola, catalogados, higienizados e arquivados no Memorial Do Deutscher Hilfsverein ao Colégio Farroupilha ${ }^{4}$.

\footnotetext{
${ }^{1}$ Wilhelm Ter Brüggen fazia parte dos 99 sócios da Sociedade Alemã de 1858. Ocupou o cargo de presidente da Deutscher Hilfsverein nos anos de 1868, 1873 e 1876. Era jornalista e cônsul da Prússia.

2 Carlos Von Koseritz participou ativamente da Sociedade Alemã e foi um defensor do futuro alemão no Rio Grande do Sul.

${ }^{3}$ Este estudo é parte integrante do projeto de pesquisa intitulado Do Deutscher Hilfsverein ao Colégio Farroupilha: entre memórias e histórias (1858-2008), coordenado pela profa. dra. Maria Helena Camara Bastos (CNPq/Fapergs/PUCRS 2011-2015).

${ }^{4}$ Com a finalidade de difundir e preservar a memória da trajetória da escola foi criado, em 2002, o Memorial Do Deutscher Hilfsverein ao Colégio Farroupilha. O espaço conta com acervo de fotografias, uniformes, livros, periódicos, mobiliário e outros objetos da cultura escolar. Ver Almeida, Bastos, Jacques (2008).
} 
O Colégio Farroupilha de Porto Alegre/RS ${ }^{5}$ é uma instituição que tem apreço pelo seu patrimônio histórico-cultural. Desde sua origem colocou em prática um método que caracterizou e exemplificou diversos tipos de ações dos colonos imigrantes alemães no Estado e que hoje pode ser estudado para diversos fins:

Os estudos que tratam da imigração alemã no Rio Grande do Sul são praticamente unânimes em apontar alguns aspectos para os quais essa etnia deu atenção especial. Trata-se da escola comunitária, difusão da imprensa, ênfase no associativismo, organização das comunidades religiosas, criação de estruturas de apoio para dinamizar e canalizar as iniciativas locais e regionais, vinculando-as a um projeto comum. (Kreutz, 1994, p. 152)

A criação de um jornal foi uma das iniciativas da escola que se tornou um importante canal de comunicação entre esta e a comunidade. No dia $1^{\circ}$ de maio de 1929 surgia o Das Band, Monatschrift der Schulen des Deutschen Hilfsvereins zu Porto Alegre, periódico mensal das escolas da Sociedade Beneficente Alemã de Porto Alegre.

\section{A Escola Mista Deutsche Hilfsvereinsschule}

$\mathrm{O}$ atual Colégio Farroupilha de Porto Alegre é uma escola que teve suas origens em salas alugadas da Comunidade Evangélica de Porto Alegre no ano de 1886, dirigida por Peter Gerlach $^{6}$ (1886-1889), inicialmente com um corpo discente masculino. A Knabenschule foi resultado da união entre os descendentes de imigrantes alemães, que se agregaram na Sociedade Beneficente Alemã (Deutscher Hilfsverein), criada em $1858 \mathrm{e}$ que mostrava, desde 1875, uma grande aspiração para a criação de uma escola.

Segundo Kreutz (1991), diversos ideais nacionalistas e liberais tinham ênfase na Prússia no início do século 19 e uma marcante repercussão no Sul do Brasil. Nesse sentido,

promoveram a difusão geral do ensino elementar, a melhoria na formação dos professores pela implantação das escolas normais, a renovação de métodos e, especialmente, a formação de uma nova mística em relação à educação sob o pressuposto de que as reformas sociais e políticas deveriam surgir pela educação. (Kreutz, 1991, p. 38)

O colégio se caracterizou por diversas mudanças, tanto em sua nomenclatura Knabenschule, Mädchenschule, Hilfsvereinschule, Hindenburgschule, Ginásio TeutoFarroupilha e Ginásio Farroupilha -, quanto em sua localização - salas da igreja Evangélica, prédio da rua São Rafael e atual localização no bairro Três Figueiras -, aspectos que marcam sua trajetória e enfatizam sua história.

Sua história compreende a fundação de uma escola de meninas em 1906, a inauguração do primeiro jardim de infância em 1911 e a criação de uma escola mista em $1929^{7}$. O ano de 1929 também foi marcado pela criação do periódico escolar, ano este em que as duas escolas da Deutscher Hilfsverein se juntaram. A escola mista foi idealizada

\footnotetext{
${ }^{5}$ Sobre a história da ABE e do Colégio Farroupilha ver Telles (1974); Hoffmeister (1986).

${ }_{7}^{6}$ O professor Peter Gerlach foi o primeiro diretor da escola.

${ }^{7}$ Após 1929, por sugestão do diretor Kramer, decidiu-se reunir, numa só classe, rapazes e meninas. Ambas as escolas passaram a funcionar no edifício da Rua São Raphael (Jacques, 2008).
} 
pelo diretor Hans Kramer e colocada em pauta do conselho escolar de 1929. Objetivava juntar na mesma turma meninos e meninas, configurando o ensino em co-educação. As aulas funcionavam na sede da escola construída em 1895, no Velho Casarão, no centro de Porto Alegre.

Figura 1

Página do jornal Das Band de $1^{\circ}$ de maio de 1929.

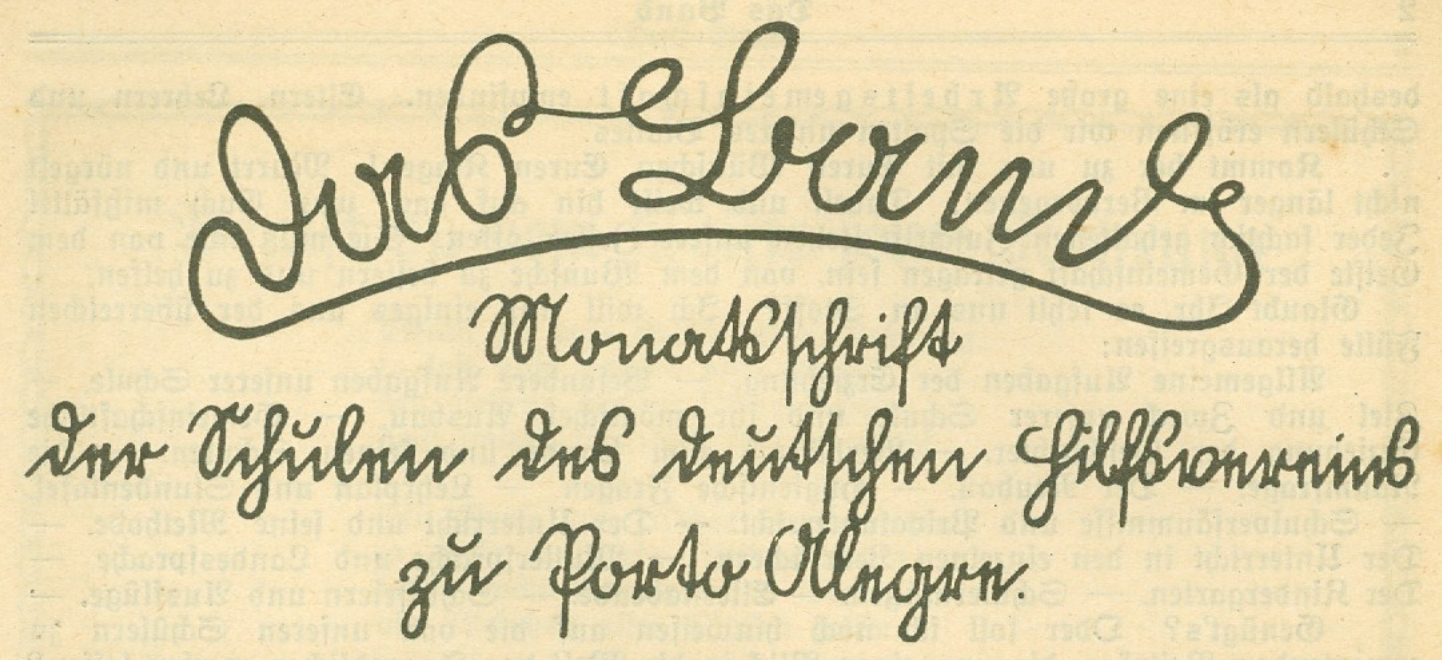

1. Jahrgang

ßorto भllegre, Den 1. Mai 1929

Nr. 1

\section{4) ay mix mollen.}

(Eine neue 3eitung? (5ibt es nidjt iđjon mehr als genug? Sit bas nid)t über= flüfijg, 3eit= und Staftwerid)wendung?

Rein, verebrte Rejer, unjere 3eitung ift teins von biejen. Die 2lufgabe, bie fie iid) geftellt hat, entipringt nidjt ber Neuerungsluit und Spielerei, jonbern fie ift von ber harten $\mathfrak{R}$ totwendigfeit gegeben.

Der unjere Sđule fennt, ober bod zu fennen meint, weik, daj ihr eins por allem fehlt: bie (5emeinidaft. (Eine Sd)ule ift fein Saufmannslaben, in bem man für mehr ober weniger (belo mehr oder minder $\mathfrak{B i f f e n ~ u n d ~ S e n n t n i f f e ~ e r w e r b e n ~}$ fann und in bem थีngebot und $\mathfrak{N a d j f r a g e ~ b e n ~} \mathfrak{B e r t}$ und bie (5üte ber $\mathfrak{B a r e}$ bejtimmen. Dieje leiber weit verbreitete Meinung weijen wir von uns. Uniere Sdule will Mienjđen bilden und exzieben. Exziebung zum Eeben, zur (5emeinfdaft aber nur burd bie (5emeinfdaft gejøeben.

Saben wir an unjerer Silfsvereinsidule jolde (5emeinjdaft? Nein! - Füblen

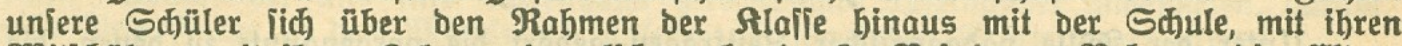
Mitjđülern, mit ifren Rehrern innerliđ verbunden? Nein! - Nebmen bie Eltern unjerer Sinber an unjerer Erziehungsarbeit, an bem Wohlergehen ber Sđule wirflidben inneren 2 nteil? Rein! - Sie zweifeln? Was glauben Sie: wieviele Eltern würben fið) heute zu einer in ben Iageszeitungen ober burd) Runbjđreiben betanntgemachten EIternverjammlung einfinben? Wieviele baben ił Nođi nidt ber 20 . Teil.

Das barf nidjt io weiter gehen. Die Sđjule barf nidht bamit erlebigt jein, baß man fein Sđjulgelb zahit, hier und ba ein wenig idjilt unb fein Sint abmelbet, wenn einem etwas nidit pajt.

Da will bas $\mathfrak{B}$ a $n$ o in bie Brejde ipringen.

Die 2 rbeit bes Erziehers ift bie idwerite aber aud bie notmenbigite von allen.

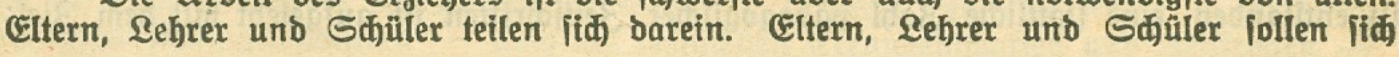

Fonte: Das Band, 1929, p. 1. 
Periódico escolar ${ }^{8}$ com tiragem mensal, inicialmente produzido em sua totalidade na língua alemã, circulou por dez anos até ser substituído pelo Relatório Mensal do Colégio Farroupilha, no início de $1939^{9}$. Editado na gestão do diretor Hans Kramer (1929-1939), mostrava, em sua primeira página, o orgulho do diretor em criar esse instrumento de comunicação.

Foram produzidas 98 edições. Destas, 76 estão no acervo do Memorial. Das edições pertencentes ao acervo são contabilizados 124 exemplares $^{10}$, distribuídos conforme a tabela abaixo.

Tabela 1

Número de exemplares do Das Band, 1929-1938, disponíveis no acervo do Colégio Farroupilha.

\begin{tabular}{|c|c|c|c|c|c|c|c|c|c|c|}
\hline & 1929 & 1930 & 1931 & 1932 & 1933 & 1934 & 1935 & 1936 & 1937 & 1938 \\
\hline Mar & - & 2 & 2 & - & 1 & - & 2 & 2 & 2 & 4 \\
\hline Abr. & - & 2 & 1 & - & 1 & 2 & 2 & 2 & 3 & 2 \\
\hline Mai. & 1 & 2 & 2 & 1 & - & 1 & 1 & 1 & 2 & 3 \\
\hline Jun. & - & - & - & - & - & 1 & 2 & 1 & 3 & 2 \\
\hline Jul. & 1 & - & 1 & 1 & 2 & 1 & 1 & 1 & 2 & 2 \\
\hline Ago. & - & - & 1 & 1 & - & - & 2 & 1 & 3 & 2 \\
\hline Set. & 2 & 1 & 1 & - & 1 & 1 & 2 & 2 & 2 & 2 \\
\hline Out. & 1 & - & 1 & 1 & 1 & 1 & 2 & 1 & 3 & 2 \\
\hline Nov. & - & - & - & 1 & - & 2 & 2 & 1 & 1 & 3 \\
\hline Dez. & 2 & - & - & 1 & 1 & 1 & 2 & 1 & 2 & 1 \\
\hline Total & 7 & 7 & 9 & 6 & 7 & 10 & 18 & 13 & 23 & 23 \\
\hline
\end{tabular}

O Das Band tem um design diferente para os jornais escolares da época e não se enquadra no padrão standard ${ }^{11}$, que era amplamente usado. A capa era constituída pelas informações básicas - nome do jornal, ano, edição e lugar de origem -, as únicas referências administrativas do periódico. Tinha grande demanda, pois era distribuído para todos os estudantes e familiares. Também havia grande divulgação devido ao patrocínio de diversas lojas alemãs, que dominavam o comércio porto-alegrense. Das edições que continham de 16 a 20 páginas, quatro a cinco delas eram destinadas para a divulgação de propagandas dos patrocinadores.

Durante a festa escolar de 1929, o diretor $\mathrm{Kramer}^{12}$ começou um processo de divulgação e de sensibilização entre os ex-estudantes e diversas lojas alemãs para patrocinarem o periódico que se iniciava. As propagandas eram de lojas geralmente localizadas no centro de Porto Alegre, algumas delas na Avenida Voluntários da Pátria.

${ }^{8} \mathrm{O}$ jornal escolar é um método criado por Celestin Freinet, que consiste em divulgar e publicar os textos livres produzidos pelos estudantes e pela comunidade escolar. Ver Freinet $(1974 ; 1977)$.

${ }^{9}$ Sobre o relatório mensal do Ginásio Teuto-Brasileiro Farroupilha, ver Almeida (2012).

${ }^{10}$ Grande parte do acervo de jornais do memorial provém de doação de ex-estudantes.

${ }_{11}^{11}$ Nome dado ao formato de jornal que possui $55 \mathrm{~cm}$. Ver Freire (2009).

12 Hans Kramer nasceu em Hannover, na Alemanha, em 1888. Foi diretor do Colégio Farroupilha, nos anos de 1929-1939, e professor de alemão para as turmas do curso primário até 1941, quando deixou a escola. Foi responsável pela criação dos jornais Das Band e Relatório Mensal do Colégio Farroupilha, bem como pela mudança do nome da escola em 1937. 
Mostravam, as propagandas, preferência pelo público alemão, tanto pelos textos, quanto pela forma que eram produzidas. No início há um maior número de propagandas que exaltam a culinária, a produção de itens e serviços dos alemães. Abaixo, pode-se observar dois exemplos de propagandas do exemplar de março de 1936, com publicidade ilustrada e acompanhada de um pequeno texto.

Figura 2

Propagandas do jornal Das Band.
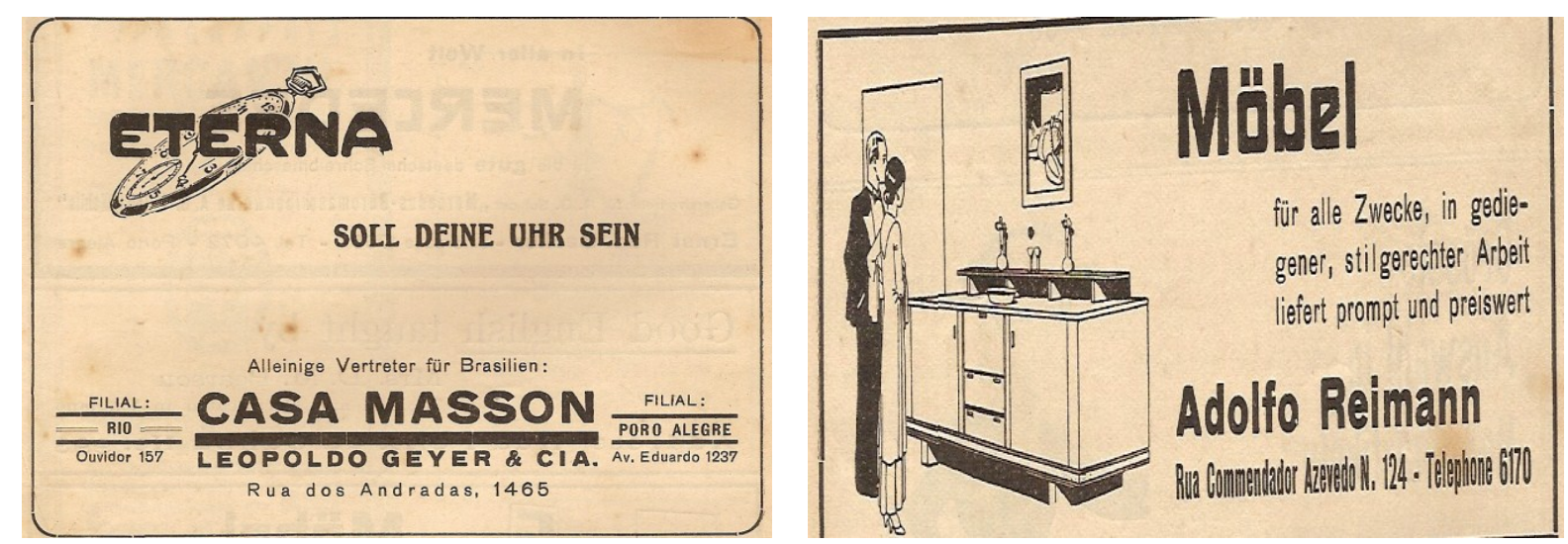

Fonte: Das Band, 1936, p. 15.

A seguir, há exemplo das traduções de algumas propagandas retiradas do número de março de 1937, que evidenciam a exaltação de produtos e serviços propriamente ditos.

Quadro 1

Propagandas do jornal Das Band.

\begin{tabular}{|l|l|}
\hline \multicolumn{1}{|c|}{ Loja/produto } & \multicolumn{1}{c|}{ Enunciado } \\
\hline Guaraná Record & A marca líder. \\
\hline Bonbonniere Woltmann & O lugar das senhoras elegantes da praça. \\
\hline Casa Masson & Dê um relógio de presente. \\
\hline Pfaff & Deixe todas as roupas de casa ajustadas. \\
\hline Livraria Herrmann & Vendendo livros e periódicos alemães. \\
\hline Leitaria Vigor & $\begin{array}{l}\text { Para o alemão o fornecedor de Leitaria Vigor. Entrega } \\
\text { gratuita em casa. Cremes, natas, melhores manteigas. }\end{array}$ \\
\hline Ebner e Aerckerle & $\begin{array}{l}\text { Na casa de um bom músico não pode faltar um } \\
\text { acordeão e gaita Hohner. }\end{array}$ \\
\hline
\end{tabular}

Fonte: Das Band, 1936, p. 15-16.

Não havia uma estrutura constante na configuração do jornal. $\mathrm{Na}$ maioria das edições, após as informações gerais, seguia-se um artigo do diretor da escola ou de algum professor, no qual se pautava o assunto que seria o cerne daquela edição. Em outras, o artigo central era feito na página seguinte e na primeira página vinha uma imagem elaborada por um estudante, que pautaria e ilustraria a edição. 
Figura 3

Edição de março de 1938 do Das Band.

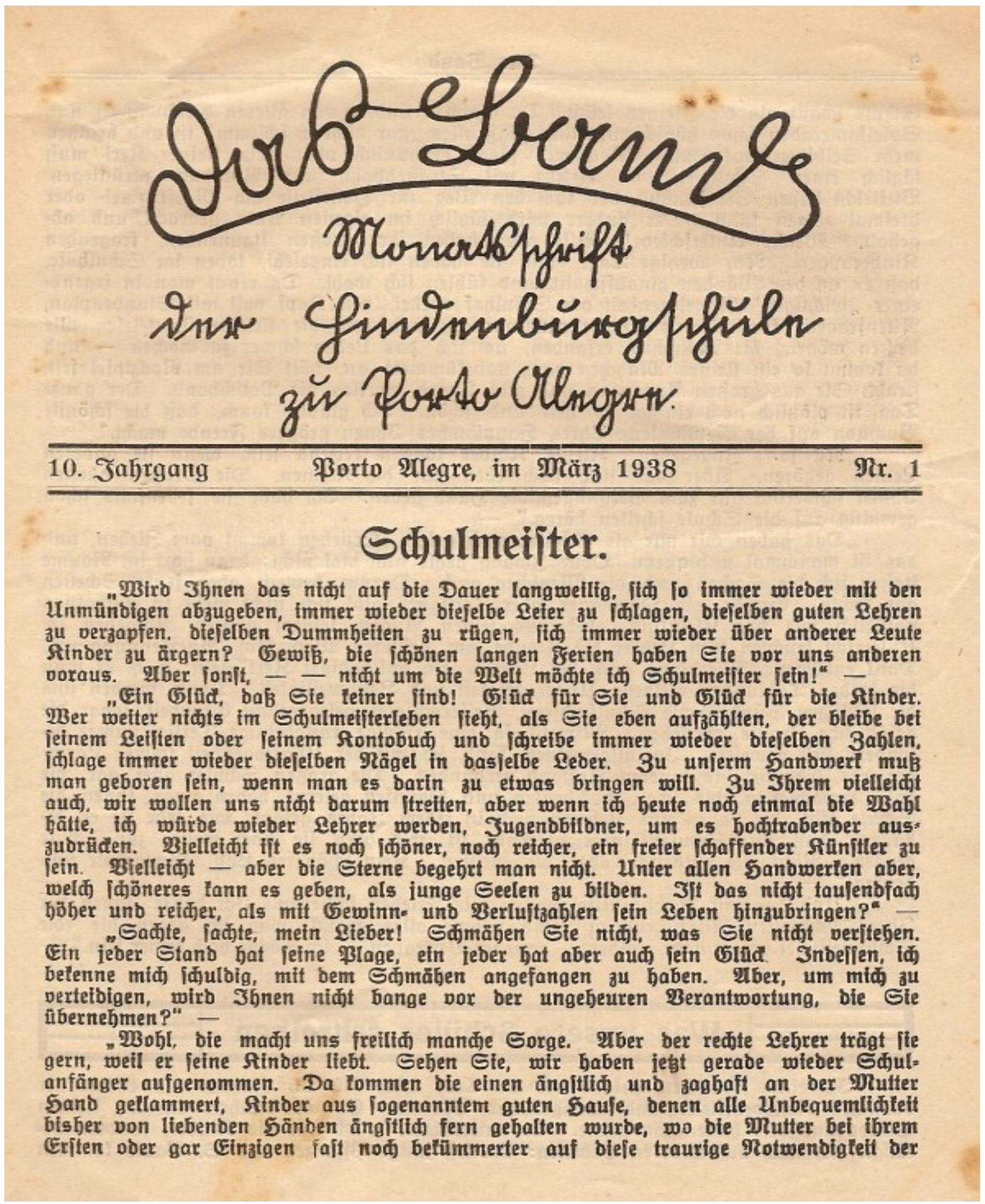

Fonte: Das Band, 1938, p. 1. ${ }^{13}$

\footnotetext{
${ }^{13}$ A edição de março de 1938 mostrava as produções dos estudantes sobre as férias escolares.
} 
Figura 4

Edição de julho de 1934 do Das Band.

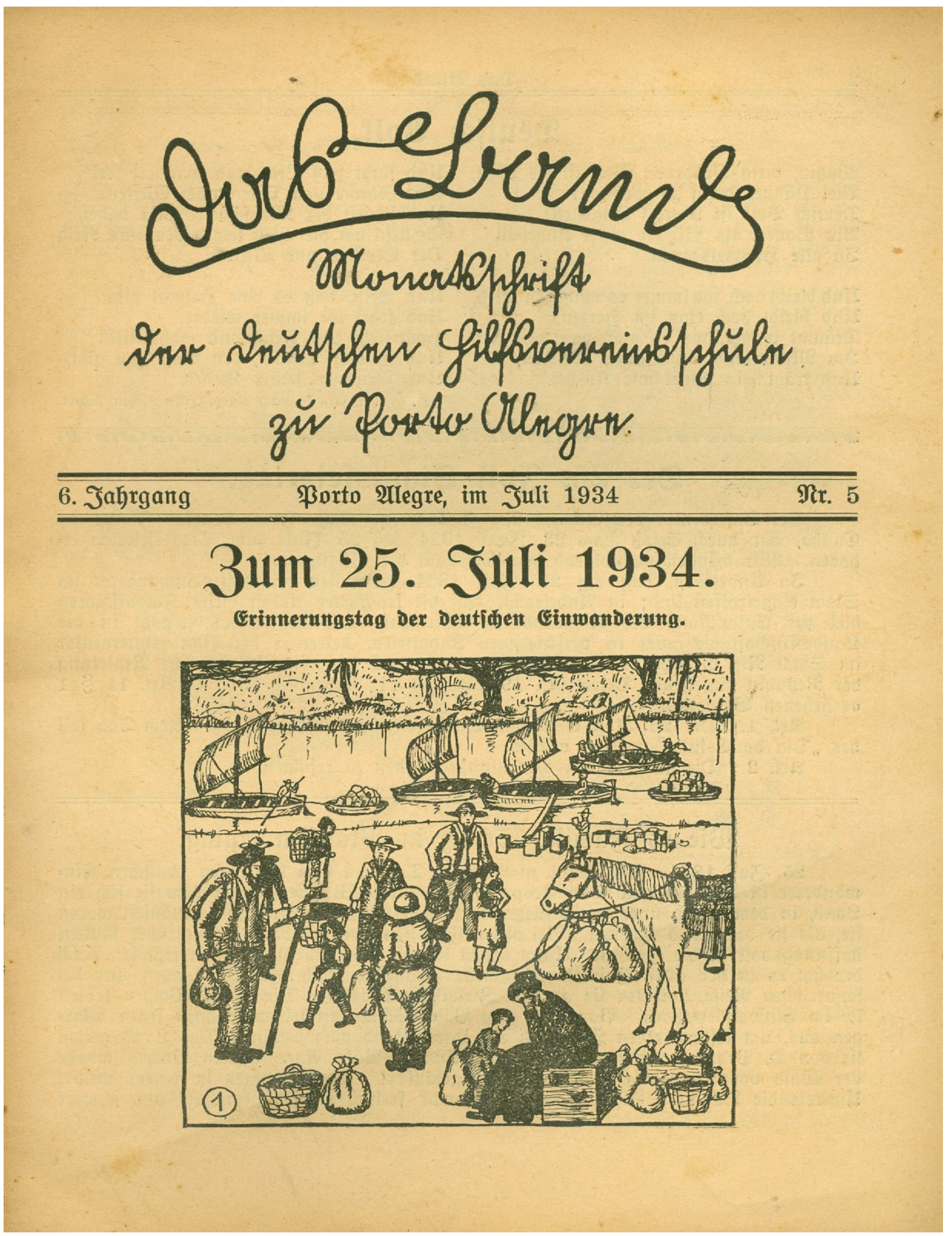

Fonte: Das Band, 1934, p. $1{ }^{14}$

\footnotetext{
${ }^{14}$ A edição de julho de 1934 continha, na capa, um desenho feito por um estudante não identificado.
} 
Pode-se observar que o jornal era, preferencialmente, produzido em língua alemã, com algumas traduções para o português. Essa premissa foi alterada ao longo de sua trajetória, com a publicação de diversos artigos em português, com ênfase na produção discente.

Tabela 2

Número de artigos em alemão e português publicados por ano.

\begin{tabular}{|c|c|c|c|}
\hline Ano & Artigos em alemão & Artigos em português & Total \\
\hline 1929 & 39 & 6 & 45 \\
\hline 1930 & 27 & 4 & 31 \\
\hline 1931 & 120 & 2 & 122 \\
\hline 1932 & 111 & 9 & 120 \\
\hline 1933 & 119 & 69 & 188 \\
\hline 1934 & 113 & 67 & 180 \\
\hline 1935 & 169 & 99 & 268 \\
\hline 1936 & 185 & 102 & 287 \\
\hline 1937 & 135 & 79 & 214 \\
\hline 1938 & 75 & 73 & 149 \\
\hline Total & 1.093 & 510 & 1.603 \\
\hline
\end{tabular}

Fonte: Memorial do Deutscher Hilfsverein ao Colégio Farroupilha.

Ao se analisar a totalidade dos artigos, percebe-se que não há grande distinção entre as produções de meninos e meninas, mas constata-se uma maior produção de artigos escritos por alunas, 726 artigos comparado a 687 de meninos.

Tabela 3

Número de colaborações de meninos e meninas por ano.

\begin{tabular}{|c|c|c|c|}
\hline Ano & Meninos & Meninas & Total \\
\hline 1929 & 9 & 10 & 19 \\
\hline 1930 & 6 & 9 & 15 \\
\hline 1931 & 46 & 48 & 94 \\
\hline 1932 & 50 & 47 & 97 \\
\hline 1933 & 85 & 73 & 158 \\
\hline 1934 & 96 & 73 & 169 \\
\hline 1935 & 116 & 138 & 254 \\
\hline 1936 & 128 & 143 & 271 \\
\hline 1937 & 85 & 114 & 199 \\
\hline 1938 & 66 & 69 & 135 \\
\hline Total & 687 & 726 & 1.413 \\
\hline
\end{tabular}

Fonte: Memorial do Deutscher Hilfsverein ao Colégio Farroupilha.

No contexto anual, há uma maior produção de artigos nos anos de 1935, 1936 e 1937 e abre-se espaço para os estudantes publicarem seus escritos. Como se pode ver na tabela abaixo, com a iminência da extinção do jornal, o número de produções dos 
estudantes diminuiu e os artigos dos professores versavam acerca do nacionalismo e da nova reforma educacional, o que indica uma mudança de postura ${ }^{15}$.

Tabela 4

Número de artigos de estudantes e professores por ano.

\begin{tabular}{|c|c|c|c|}
\hline Ano & Estudantes & Professores & Total \\
\hline 1929 & 19 & 26 & 45 \\
\hline 1930 & 15 & 16 & 31 \\
\hline 1931 & 94 & 28 & 122 \\
\hline 1932 & 97 & 23 & 120 \\
\hline 1933 & 158 & 30 & 188 \\
\hline 1934 & 169 & 12 & 181 \\
\hline 1935 & 254 & 14 & 268 \\
\hline 1936 & 271 & 16 & 287 \\
\hline 1937 & 199 & 15 & 214 \\
\hline 1938 & 135 & 14 & 149 \\
\hline Total & 1413 & 194 & 1.607 \\
\hline
\end{tabular}

Fonte: Memorial do Deutscher Hilfsverein ao Colégio Farroupilha.

Em síntese, pode-se ver que os textos dos professores tinham mais freqüência nos primeiros anos do periódico. Os artigos localizavam-se nas primeiras páginas e introduziam o tema da publicação. Nos primeiros dois anos de publicação, os textos de estudantes e professores apareciam em pequenas proporções. Após a década de 1930, mostrou-se uma preferência nas escritas discentes.

\section{As escritas dos estudantes: Was Unsere Schüler Schreiben}

A seção Was Unsere Schüler Schreiben, (O que os nossos estudantes escrevem), era a mais expressiva do jornal Das Band, pois estimulava o corpo discente do curso primário e do curso ginasial a publicar suas redações ${ }^{16}$ que resultavam das atividades desenvolvidas em sala de aula e de concursos promovidos pela direção da escola. $\mathrm{O}$ tema escrito era, geralmente, livre, salvo em algumas edições que pautavam obrigatoriamente sobre as férias, março, no período de volta às aulas, e sobre a imigração alemã, julho, no período de comemoração da vinda dos primeiros imigrantes alemães. Nas outras redações, os temas eram pautados pelo desejo do estudante ou pela escolha do diretor e do professor. Pode-se pensar que a publicação não decorria só de um desejo dos estudantes, mas de uma ingerência de professores e do diretor.

As redações mostram a escolha dos estudantes em produzir textos que traziam um pouco de suas histórias de vida, comuns nos anos iniciais do curso primário:

\footnotetext{
${ }^{15} \mathrm{O}$ último ano do Das Band foi repleto de artigos que exaltavam o sucesso do jornal e, também, de dúvidas acerca do futuro.

${ }^{16}$ Segundo Freinet (1974, p. 82), o jornal escolar era "utensílio indispensável ao intercâmbio escolar, sobretudo no ensino primário. [...] Pela troca de textos impressos poderemos entrar em contacto com meios familiares, industriais, comerciais, agrícolas, folclóricos e artísticos e estes conhecimentos constituirão um alargamento benéfico do nosso conhecimento escolar."
} 
Um dia, em que não tinha nenhum livro para ler, busquei um de ti tio. Mas que horror! O livro só 'tratava de gatúnos que iam de madrugada ás casas roubar. Comecei a ler; mas' quando notei que éram historias de gatúnos, imediatamente guardei o livro. A noite, fiquei com medo de que alguêm entrasse no meu quarto. Desse dia em diante não busquei mais livros de meu tio. (Zimmer, 1937, p. 8)

O texto abaixo marca um importante evento, que foi a volta às aulas. As principais redações são as que descrevem o espaço e as ações executadas nas férias:

Nas férias eu fui para Ipanema. Eu pesquei muitos peixes, depois eu larguei todos os peixes no meu açude. Nos também tomamos banho. Ás vezes eu fui passear com a minha mãe e com a minha irmã. (Engel, 1938, p. 8)

Outro assunto de preferência dos estudantes era contar sobre os animais de estimação ou idas ao circo:

Eu gosto muito de ir ao circo. Por causa dos palháços. No circo queirolo eu gostei do anão. Ele podia-se parar na cabeça. Então toda criançada ria muito. Ele trabalhava com um palhaço muito engraçado. Havia outras coisas de que eu também gostei. (Walther, 1934, p. 5)

No texto abaixo, pode-se ver que os textos passavam pela subjetividade de cada estudante ao representar seus sentimentos:

Éra uma linda manhã de verão. Tinha ido á missa e na igreja visto uma velhinha parada á porta pedindo esmolas. A cada pessoa que passava, estendia a mão para ver si alguem se compadecia dela e lhe dava algum niquel, Mas éra triste vêr que quasi ninguem lhe dava alguma cousa. $E$ meu plano estava feito. Ao sair da igreja dei á pobre velha a minha passagem de bonde e fui a pé para casa. $E$ assim não só tinha praticado uma boa ação, como tambem tinha feito um lindo passeio. (Lüderitz, 1937, p. 6)

Essas redações são, segundo Bishop (2010), redigidas na primeira pessoa com "narrações de acontecimentos vividos" (p. 2). São expressões de escritas de si, em que o autor é o objeto mais ou menos autêntico de seu texto. Nota-se frases curtas, erros de ortografia e repetição de palavras:

Hoje vais tomar banho, Bummel, disse minha mãe certo dia para o nosso cachorro. Bummel não gosta de tomar banho. Ele é muito inteligente e compreende tudo que dizemos. A água para Bummel estava pronta e minha mãe chamou-o. Bummel não apareceu. Começamos a procurá-lo. Mas em vão. Bummel desaparecera. (Haessler, 1934, p. 6) 


\section{A imigração alemã nas páginas do Das Band}

O periódico, como representante das manifestações culturais e sociais da comunidade do Ginásio Teuto-Farroupilha ${ }^{17}$ aborda, com muita ênfase, os assuntos ligados ao processo de imigração alemã no Rio Grande do Sul em 1824.

\section{Figura 5}

Desenhos nas capas dos Das Band.

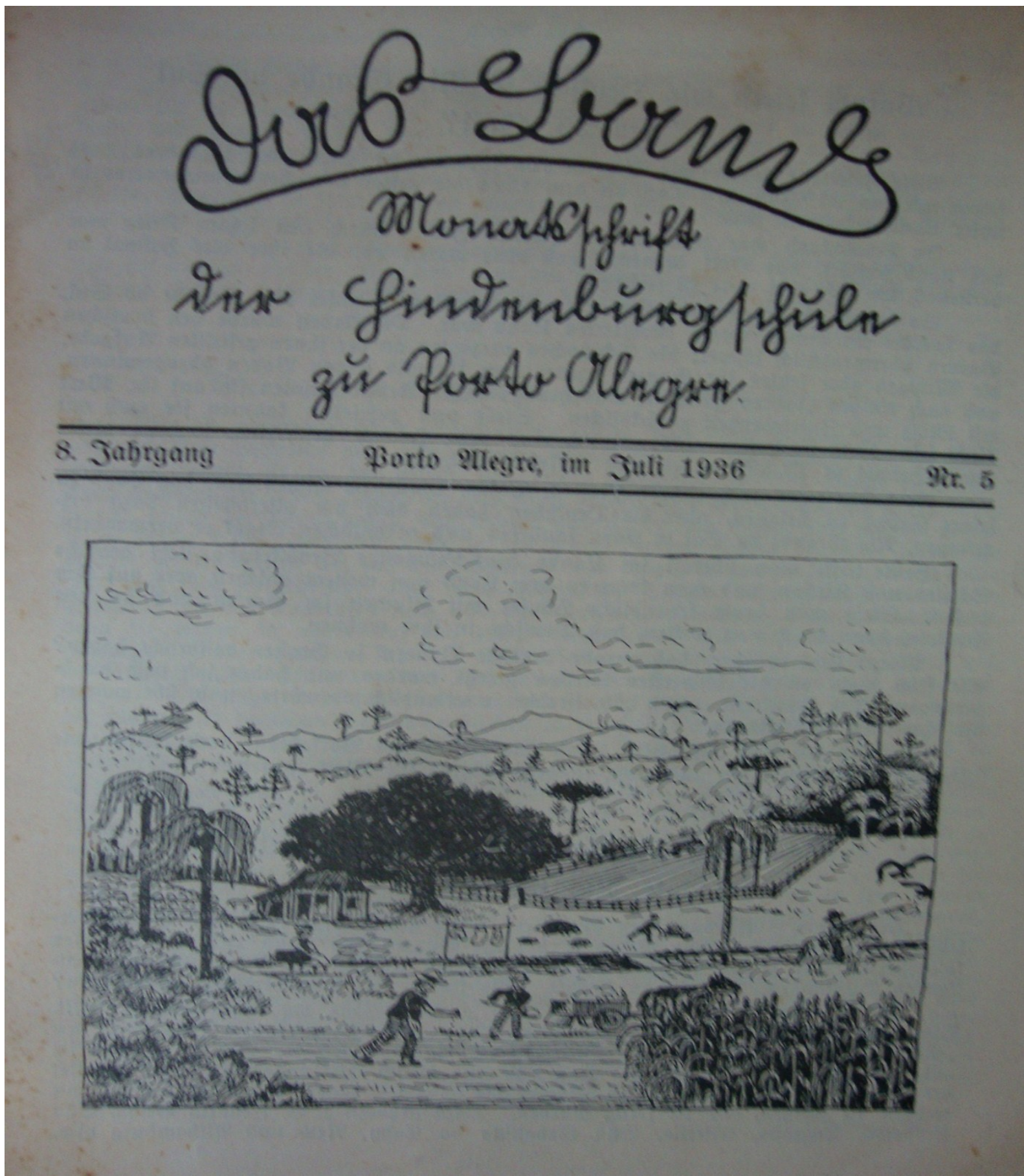

Fonte: Das Band, julho de 1936, p. 1.

17 Denominação adotada em 1937. Ver Telles (1974), Hoffmeister (1986). 
As edições do mês de julho eram marcadas por números comemorativos, que vinham ilustrados com signos. Segundo Martine Joly (2007), esses devem ser considerados pelo seu modo de produção de sentido, isto é, de interpretações. De fato, um signo só é signo se expressar idéias e provocar atitudes interpretativas. O que sintetiza a intenção da presença de algumas imagens em levar a comunidade escolar a interpretar o contexto do imigrante que, posteriormente, era expresso por meio de artigos. As imagens eram produzidas pelos estudantes para elucidar e expor seus textos como, por exemplo, a imagem acima, ${ }^{18}$ que ilustra o início da colonização, o trabalho e as condições geográficas do Rio Grande do Sul.

Após a representação imagética seguiam-se as escritas discentes, que nos exemplares de comemoração tinham um tamanho maior do que nos outros, cerca de 15 a 25 linhas, e contrastavam com a produção dos outros meses, que não passavam de 5 linhas. Pode-se ver, nos excertos abaixo, fragmentos que caracterizam a visão dos estudantes sobre como aconteceu a imigração e qual foi a reação dos colonos ao chegar na nova terra. Essa percepção é produto da aprendizagem de temas trabalhados na sala de aula:

Há mais ou menos 25 anos meus pais vieram para o Brasil. Naquele tempo fazia-se propaganda para a emigração em todas as partes da Europa. E meus pais vieram com muitos outros ao Brasil. (Stillner, 1935, p. 3)

Vendo-se hoje as cidades de S. Leopoldo, N. Hamburgo, ljuí, S. Cruz, e outras, quasi não se pode crer que há um século nestes lugares só havia mata virgem ou campo silvestre. (Schall, 1936, p. 4)

A conselho de da imperatriz $D$. Leopoldina, que era uma princesa Austríaca e sabia avaliar o trabalho dos alemães, D. Pedro I mandou vir da Alemanha colonos vigorosos e trabalhadores. Assim aconteceu em março de 1824, um navio a vela partiu do porto alemão, conduzindo 43 emigrantes, que deixaram sua pátria a fim de iniciarem a colonização do Rio Grande do Sul. (Schall, 1936, p. 15)

Os três excertos caracterizam um pensamento geral nacionalista e ufanista de que $o$ trabalho alemão era o mais forte e superior. O discurso do professor Bruno Klein, dos estudantes Waltraut Schall e Frans Stillner, mostram as dificuldades enfrentadas e exaltam a bravura e força do colono alemão.

Esses argumentos são deixados de lado à medida em que o jornal se aproxima do ano de 1938. Os estudantes passam a escrever sobre a história de Porto Alegre, salientar as contribuições que a sociedade alemã deu para a cidade e sobre o ideal de pátria e nação:

Estamos aqui reunidos, para comemorar, em festa e piedade, a vinda da primeira leva de emigrantes alemães ao nosso querido Rio Grande. A 25 de julho de 1824 desembarcavam, no passo do Rio dos Sinos, hoje São Leopoldo, as primeiras famílias, que foram alojadas pelo vale do mesmo

\footnotetext{
${ }^{18}$ A imagem da edição de julho de 1936, assim como a maioria presente nas capas, não apresenta identificação do estudante que a produziu.
} 
rio e fundaram sucessivamente, essas localidades florescentes. [...] Os primeiros anos foram de árduo sofrimento. [...] Os pobres colonos viram-se abandonados a si próprios, sem auxílios, faltos de meios, sem escolas, sem defesa, sem templo para atender aos seus anseios, sua dor e sua fé. (Klein, 1931, p. 1)

Os artigos dos estudantes também insistem em mostrar que, por vários anos, o contexto não era de fartura, pelo contrário, era de sofrimento. No discurso abaixo, outro fator resultante da imigração foi evidenciado - a presença dos índios nas áreas que os imigrantes ocuparam:

No ano de 1824 viéram os primeiros alemães para São Leopoldo Novo Hamburgo. A viagem não éra bôa porque tinham de viajar em navi a véla. Quando chegaram a São Leopoldo, Dom Pedro I deu-Ihes um pedaço de terra. Custou muito para eles tirarem o mato. Mas tambem havi indios lá, que mataram muitos alemães, tambem os alemães mataram índio: Os alemães fizéram dos troncos das arvores as suás casas. (Herman, 1936, p. 18)

O discurso do presidente W. Mücke sintetiza uma visão ufanista que era exposta nos primeiros anos do periódico:

Que sempre permanecerá o dever de honra do Hilfsverein, colaborar para a manutenção e o cultivo da língua alemã, dos costumes e da cultura alemã na nossa pátria brasileira, por meio do sustento de uma boa escola alemã. (1909 apud Jacques, 2008, p. 32)

Com o Estado Novo, começa-se a enfatizar que a pátria do alemão é o Rio Grande do Sul. Diversos artigos mostram como o imigrante se instalou e se adaptou de forma positiva à nossa cultura e geografia. Há um esforço em dissociar-se da visão ufanista, difundida nos primeiros anos de publicação. 
Figura 6

Poema discente sobre imigrantes.

8

Das Banto

A cuia de chimarrão.

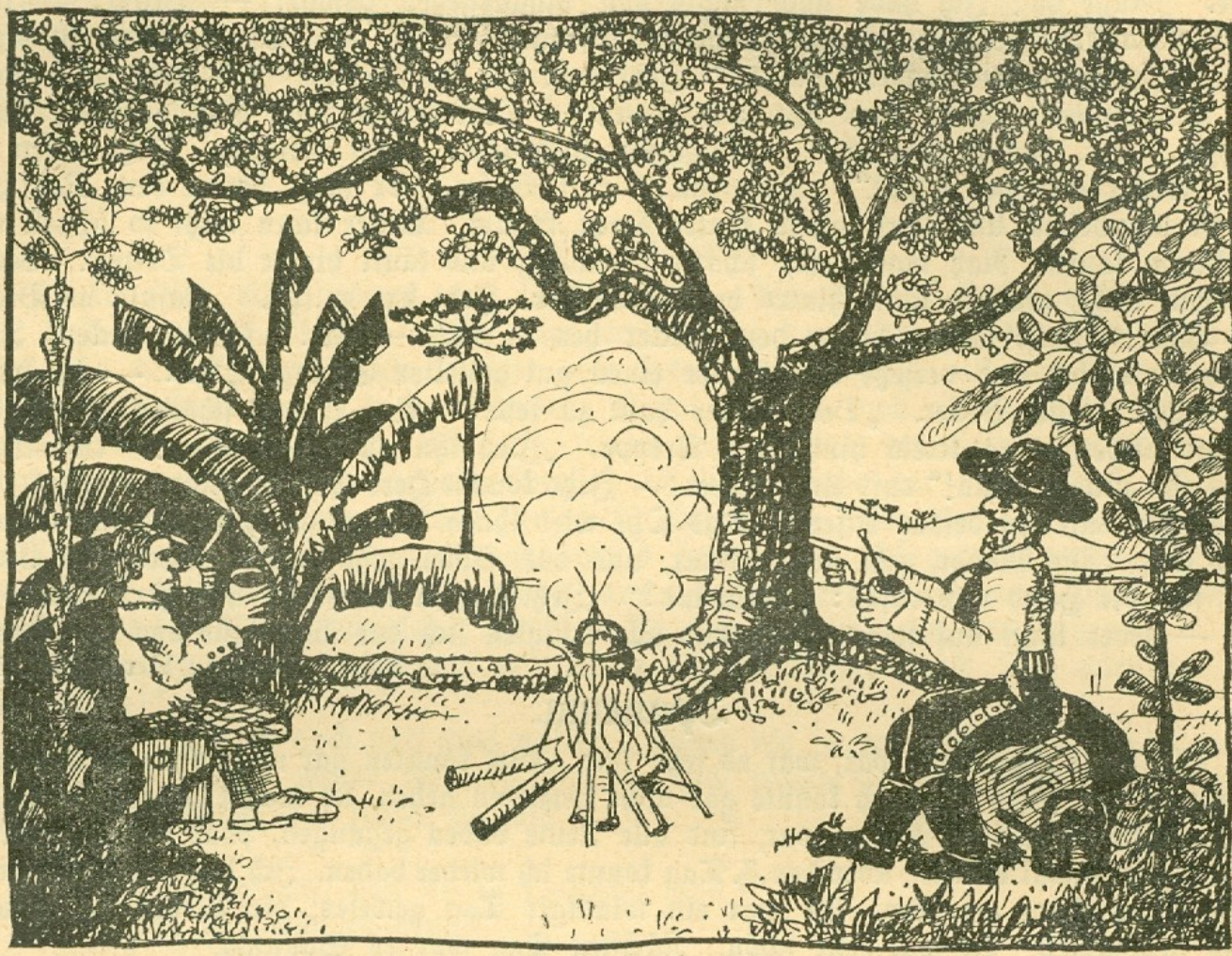

1. „Alemão está sentado

Com uma cuia na mão,

Chupa da bomba esquentada, queima a boca com o chimarrão".

2. „Queima a boca não senhor, Está acostumado a chupar, Chupa todo o dia Como póde se queimar?‘

3. „Como! póde-se queimar, Ora bolas, muito bem, O chimarrão tá muito quente, Não só tú, pois eu tambem..."
4. „Não só tú, pois eu tambem? Como isso pódes dizer? Vou te dar uma bofetada, Cuidado, que vai doer!"

5. „Camarada, cuide lá, Com gaúchos tu não vens, Cala a boca agora mesmo, Senão uma paúlada tens!“

6. E no diálogo sai briga Se derrama o chimarrão, Os dois brigões vão embora, O mate espalha-se pelo chão.

7. E aí está a cuia

Com o interior derramado,

A bomba ainda quente

Jaz no lugar desastrado.

(5ediđt und Зeiđnung von $\Re$. $\mathfrak{B e r ( j t , ~ S I . ~} 6$

Fonte: Das Band, 1937, p. 8. 
A imagem acima mostra o poema feito pelo estudante Raul Bercht e demonstra a premissa do alemão que virou gaúcho. Nela, o descendente de imigrante se apropriou de um dos símbolos do Rio Grande do Sul, o chimarrão. No texto que acompanha o artigo pode-se perceber que ele se sente um gaúcho e exige que seja tratado como tal. As redações que tratavam sobre a imigração alemã resultavam de um trabalho didático elaborado, geralmente, no mês de julho, para comemoração do Dia do Colono, e revelam a subjetividade de cada estudante, que era descendente de alemão e se sentia pertencente ao Brasil.

Figura 7

Edição de outubro de 1938.

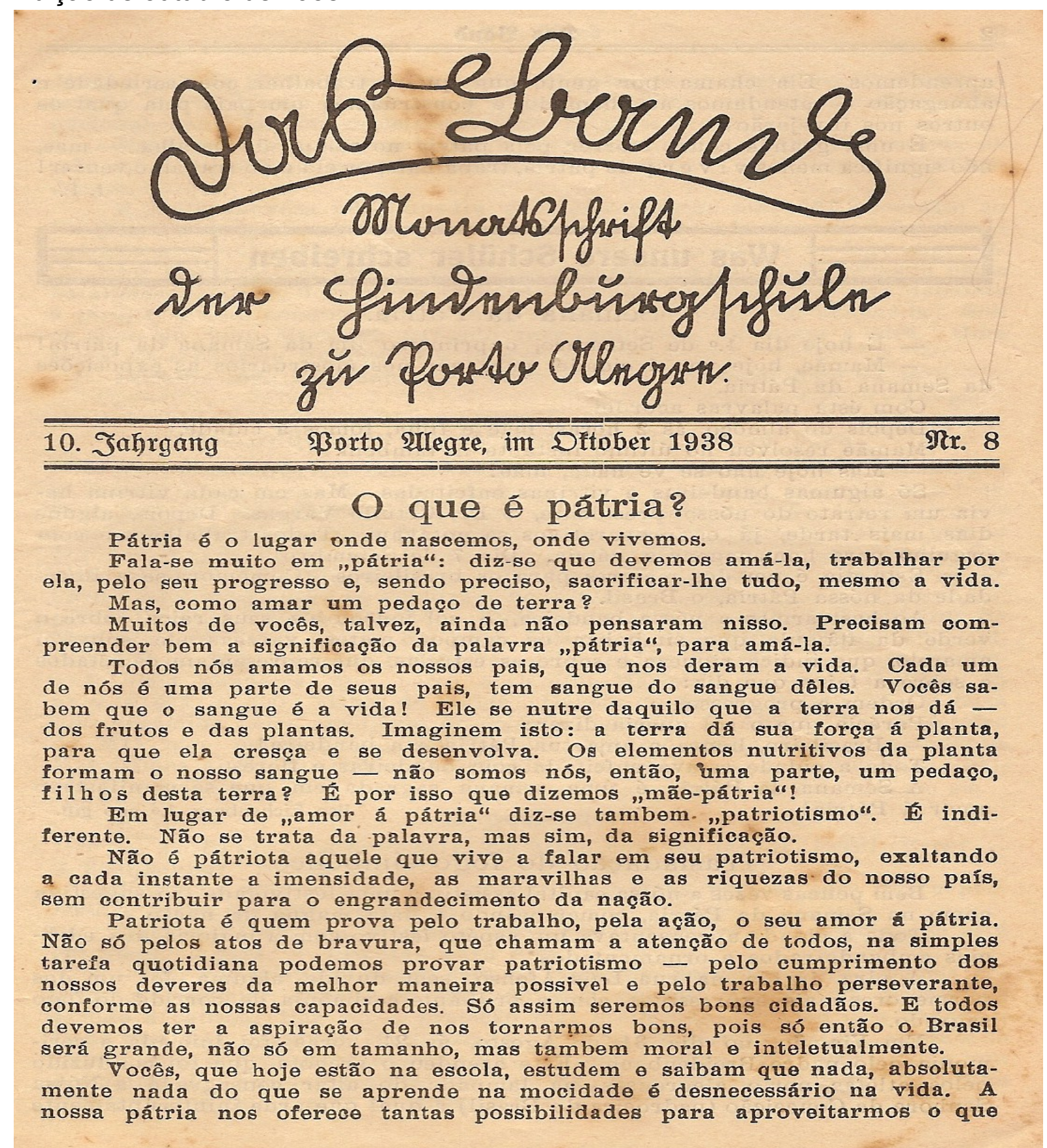

Fonte: Das Band, 1938, p. 1. 
Os excertos que seguem são de dois artigos publicados nas edições de outubro e novembro de $1938^{19}$ e expressam algumas das propostas criadas pelo governo federal para nacionalizar o ensino:

O que é pátria? Pátria é o lugar onde nascemos, onde vivemos. Fala-se muito em pátria: "diz-se que devemos amá-la, trabalhar por ela, pelo seu progresso, e sendo preciso, sacrificar-lhe tudo, mesmo a vida". Mas, como é amar um pedaço de terra? [...] Patriota é quem prova pelo trabalho, pela ação, o seu amor pela pátria. (Compagnoni, 1938, p. 1)

Lições de nacionalismo

Professor de nacionalismo. Função bem interessante esta. Nova. Recem criada. Antes não existia. Não que se desconhecesse o nacionalismo, mas porque se vivia vendo uma realidade nacional sob um prisma um tanto comodista. Comodismo bem brasileiro. "Vamos deixar como está pra ver como fica". Havia a convicção de que se faria uma grande nação simplesmente deixando rolar o tempo, sem preocupações de coordenar os fatores que integram o grande-todo. Puro determinismo. (Compagnoni, 1938, p. 1)

A presença de um professor de nacionalismo fez com que esse tipo de publicação pautasse o imaginário do estudante, colocando-o a pensar em toda a trajetória no pensamento de ser alemão:

Todos trabalharam com orgulho para homenagear a Pátria. Dia. 7 de Setembro! Este dia é um dos maiores para os brasileiros. Comemora-se a liberdade da nóssa Pátria, o Brasil. Ao hastearmos a nóssa bandeira, o sol lançou os seus raios sobre o verde da flâmula que simboliza os campos, matos, varzeas etc. sobre o amarelo, que indica riqueza e sobre as estrelas, que representam os estados e sobre a faixa que diz: Ordem e progresso. Parécia que o sol queria dizer: Brasileiro, honra e ama tua Pátria e a bandeira! Toda a cidade estava enfeitada com bandeiras e flores. A Semana da Pátria é uma semana sagrada em que se manifesta o amor á Pátria! (Eichenberg, 1938, p. 2)

A partir do ano de 1937, e em todo o ano de 1938, constatam-se diversas diferenças na estrutura do periódico: maior número de artigos dos alunos escritos em português, a totalidade da produção realizada pelos professores começa a ser feita em português, aumento do número de imagens que reproduzem o cotidiano do alemão que virou gaúcho e as temáticas dos artigos tenta mudar o conteúdo do periódico, nacionalizando-o.

\section{Considerações finais}

Em dezembro de 1938 publicou-se a última edição do jornal. O Das Band foi substituído pelo periódico Relatório Mensal do Colégio Farroupilha (1939). Para Kramer, "essa nova caminhada se daria com o mesmo sucesso e aperfeiçoamento" (1938, p. 1). Essa substituição decorreu das políticas de nacionalização do ensino, que resultaram do golpe do Estado Novo em 1937, pelo então presidente Getúlio Vargas. O ato de

\footnotetext{
${ }^{19}$ Luiz Compagnoni foi contratado em 1937 para ser o professor da nova disciplina criada pelo Ministério da Educação: Nacionalismo e Civilidade.
} 
nacionalização do ensino foi uma das características do período do Estado Novo que impôs ao país inteiro, em programas oficiais, uma língua "uniforme e estável" (Faria, 1991, p. 9), que condenava as interferências de outras línguas no Brasil.

Foi essa nacionalização compulsória que fez com que surgisse o periódico Relatório Mensal do Colégio Farroupilha, desenvolvido durante o ano de 1939, e que trazia artigos, preferencialmente, em língua portuguesa, que dissociavam a imagem do Colégio Farroupilha de uma escola alemã.

O Das Band foi um periódico que se caracterizou pela mutabilidade, que se adaptou às diversas condições políticas e sociais e cumpriu, com sucesso, a missão de ser elo de comunicação entre escola e comunidade, bem como de fomento da produção dos estudantes. A escola só voltaria a publicar um periódico escolar em 1945, o Clarim, criado pelo Grêmio Estudantil da escola.

\section{Referências}

ALMEIDA, Doris Bittencourt. Propagandas na revista O Clarim: discursos que produzem identidades. CONGRESSO LUSO-BRASILEIRO DE HISTÓRIA DA EDUCAÇÃO, 8, 2010, São Luis. Anais ... São Luis: SBHE, 2010.

ALMEIDA, Doris Bittencourt. As marcas do novo: do Colégio Alemão ao Colégio Farroupilha nas páginas do Das Band (1937-1939). CONGRESSO LUSO BRASILEIRO DE HISTÓRIA DA EDUCAÇÃO, 9, 2012, Lisboa. Actas ... Lisboa: Instituto de Educação da Universidade de Lisboa, 2012.

BASTOS, Maria Helena Camara. A Revista do Ensino do Rio Grande do Sul (1939-1942): o novo e o nacional em revista. Pelotas: Seiva, 2005.

BASTOS, Maria Helena Camara; ERMEL, Tatiane de Freitas. Infâncias Escritas: O jornal A Voz da Escola (1936-1938). CONGRESSO BRASILEIRO DE HISTÓRIA DA EDUCAÇÃO, 6, 2011, Vitória. Anais ... Vitória: SBHE, 2011.

BISHOP, Marie-France. Racontez vos vacances...: histoires des écritures de soi à l'école primaire (1882-2002). Grenoble: PUG, 2010.

COMPAGNONI, Luiz. Lições de nacionalismo. Das Band, Porto Alegre, nov., 1938, p. 1-2.

COMPANONI, Luiz. O que é pátria? Das Band, Porto Alegre, out., 1938, p. 1-2.

CUNHA, Maria Teresa Santos. Civilidade em textos: estudo sobre um jornal manuscrito infantil (1945-1952). CONGRESSO LUSO-BRASILEIRO DE HISTÓRIA DA EDUCAÇÃO, 8, 2010, São Luis. Anais ... São Luis: SBHE, 2010.

DREHER, Martin N.; RAMBO, Arthur Blásio; TRAMONTINI, Marcos Justo (orgs.). Imigração \& imprensa. Porto Alegre: Est, 2004.

EICHENBERG, Ilse. Semana da Pátria. Das Band. Porto Alegre, out., 1938, p. 2.

ENGEL, Willi. Sem título. Das Band. Porto Alegre, mar., 1938, p. 8-9.

FREIRE, Eduardo Nunes. O design no jornal impresso diário: do tipográfico ao digital. Revista Galáxia, São Paulo, n. 18, 2009, p. 291-310.

FREINET, Celéstin. O jornal escolar. São Paulo: Estampa, 1974.

FREINET, Celéstin. A leitura pela imprensa na Escola. Porto: Firmeza, 1977.

HAESSLER, Arthur. Sem título. Das Band. Porto Alegre, nov., 1934, p. 6-7. 
HERMAN, Curt. 25 de Julho. Das Band, Porto Alegre, jul., 1936, p.18.

HOFMEISTER FILHO, Carlos. 1886-1996 Colégio Farroupilha: 100 anos de pioneirismo. Porto Alegre, 1996.

JACQUES, Alice R. 150 anos da Associação Beneficente e Educacional de 1858. Porto Alegre: $A B E, 2008$

JACQUES, Alice; BASTOS, Maria Helena Camara. Cartinhas à diretora: escrita epistolar dos estudantes do curso primário do Colégio Farroupilha (Porto Alegre/RS, 1948-1966). In: ENCONTRO DA ASSOCIAÇÃO SUL-RIO-GRANDENSE DE PESQUISADORES EM HISTÓRIA DA EDUCAÇÃO, 17, 2011, Santa Maria. Anais ... Santa Maria: Asphe, 2011.

JOLY, Martine. Introdução à análise de imagem. Campinas: Papirus, 2007.

KLEIN, Bruno. Sem título. Das Band. Porto Alegre, jul., 1931, p. 1-2.

KREUTZ, Lúcio. Escolas da imigração alemã no Rio Grande do Sul: perspectiva histórica. In: MAUCH, Claudia; VASCONCELLOS, Naira (orgs.). Os alemães no sul do Brasil. Canoas: Ulbra, 1994, p. 149-161.

KREUTZ, Lúcio. O professor paroquial: magistério e imigração alemã. Porto Alegre: Ufrgs, 1991.

LÜDERITZ, Harry. Sem título. Das Band. Porto Alegre, ago., 1937, p. 8.

MAUCH, Claudia; VASCONCELLOS, Naira. Os alemães no sul do Brasil. Canoas: Ulbra, 1994.

MOGARRO, Maria João. Escola querida, que és o despertar da nossa educação: a escrita infantil nos jornais escolares portugueses. CONGRESSO LUSO-BRASILEIRO DE HISTÓRIA DA EDUCAÇÃO, 8, 2010, São Luis. Anais ... São Luis: SBHE, 2010.

SCHALL, Waltraut. Imigração alemã. Das Band. Porto Alegre, jul., 1936, p. 15.

SPALDING, Walter. História de Porto Alegre. Porto Alegre: Sulina, 1974.

STILLNER, Frans. Imigração alemã. Das Band. Porto Alegre, jul., 1936, p. 15.

TELLES, Leandro. Do Deutscher Hilfsverein ao Colégio Farroupilha 1858/1974. Porto Alegre: Globo, 1974.

WALTHER, Perly. Sem título. Das Band. Porto Alegre, nov., 1934, p. 5-6.

ZIMMER, Helga. Sem título. Das Band. Porto Alegre, ago., 1937, p. 8.

ALICE RIGONI JACQUES é estudante do curso de doutorado em Educação na Pontifícia Universidade Católica do Rio Grande do Sul e coordenadora do Memorial do Deutscher Hilfsverein ao Colégio Farroupilha.

Endereço: Rua João Ernesto Schmidt, 251/708 - 91210-125 - Porto Alegre - RS Brasil.

E-mail: alice rigoni@hotmail.com. 
LUCAS COSTA GRIMALDI é estudante do curso de História na Pontifícia Universidade Católica do Rio Grande do Sul, bolsista de iniciação científica PibicCNPq e estagiário no Memorial Do Deutscher Hilfsverein ao Colégio Farroupilha. Endereço: Rua Chile, 827/402 - 90670-140 - Porto Alegre - RS - Brasil.

E-mail: lucascgrimaldi@gmail.com.

Recebido em agosto de 2012.

Aceito em janeiro de 2013. 